\title{
The Costs of Alcohol, Illegal Drugs, and Tobacco in Canada, 2002*
}

\author{
JÜRGEN REHM, PH.D., ${ }^{\dagger}$ WILLIAM GNAM, M.D., FRCP(C), PH.D., ${ }^{\dagger}$ SVETLANA POPOVA, M.D., PH.D., ${ }^{\dagger}$ \\ DOLLY BALIUNAS, M.SC., ${ }^{\dagger}$ SERGE BROCHU, PH.D., ${ }^{\dagger}$ BENEDIKT FISCHER, PH.D.,${ }^{\dagger}$ JAYADEEP PATRA, PH.D.,${ }^{\dagger}$ \\ ANNA SARNOCINSKA-HART, M.A., AND BENJAMIN TAYLOR, M.SC. ${ }^{\dagger}$
}

Centre for Addiction and Mental Health, 33 Russell Street, Room 2035B, Toronto, Ontario M5S 2S1, Canada

\begin{abstract}
Objective: The aim of this study was to estimate costs attributable to substance use and misuse in Canada in 2002. Method: Based on information about prevalence of exposure and risk relations for more than 80 disease categories, deaths, years of life lost, and hospitalizations attributable to substance use and misuse were estimated In addition, substance-attributable fractions for criminal justice expenditures were derived. Indirect costs were estimated using a modified human capital approach. Results: Costs of substance use and misuse totaled almost Can. $\$ 40$ billion in 2002 . The total cost per capita for substance use and misuse was about Can. \$1,267: Can. \$463 for alcohol, Can. \$262 for illegal drugs, and Can. \$541 for tobacco. Legal sub-
\end{abstract}

stances accounted for the vast majority of these costs (tobacco: almost $43 \%$ of total costs; alcohol: $37 \%$ ). Indirect costs or productivity losses were the largest cost category (61\%), followed by health care $(22 \%)$ and law enforcement costs (14\%). More than 40,000 people died in Canada in 2002 because of substance use and misuse: 37,209 deaths were attributable to tobacco, 4,258 were attributable to alcohol, and 1,695 were attributable to illegal drugs. A total of about 3.8 million hospital days were attributable to substance use and misuse, again mainly to tobacco. Conclusions: Substance use and misuse imposes a considerable economic toll on Canadian society and requires more preventive efforts. (J. Stud. Alcohol Drugs 68: 886-895, 2007)
$\mathrm{T}^{\mathrm{H}}$ HE BURDEN AND COST OF SUBSTANCE USE and misuse in established market economies is enormous (Anderson and Baumberg, 2006; Andlin-Sobocki and Rehm, 2005; Collins and Lapsley, 2002; Ezzati et al., 2002; Harwood, 2000), and Canada is no exception. The last systematic estimate on the burden of substance use and misuse in Canada was undertaken a decade ago for the year 1992 (Single et al., 1996, 1998, 1999). The overall cost of substance use and misuse for that year was estimated at Can. $\$ 18.5$ billion, which represented Can. $\$ 649$ per capita. Legal substances (i.e., alcohol and tobacco) accounted for most of these costs. The study proved to be a valuable

Received: February 8, 2007. Revision: July 12, 2007.

*This study was based on a contract, not a grant. This contribution is based on research within the framework of the Second Canadian Study on Social Costs of Substance Abuse, which has received funding from various sources, under the umbrella of the Canadian Centre on Substance Abuse. The following Canadian institutions contributed to this study: Addictions Foundation of Manitoba; Alberta Alcohol and Drug Abuse Commission; British Columbia Ministry of Health Services; Canadian Centre on Substance Abuse; Canadian Institutes of Health Research, Institute of Neurosciences, Mental Health and Addiction; Centre for Addiction and Mental Health; Health Canada; Ministère de la Santé et des Services sociaux, Québec; New Brunswick Department of Health and Wellness; Nova Scotia Office of Health Promotion and Public Safety; and Emergency Preparedness Canada. The authors are grateful to these organizations for their generous support and contributions. The protocol of the study was approved by the Research Ethics Committee of the Centre for Addiction and Mental Health, Toronto, Ontario, Canada. resource for policy making and health care planning in Canada. However, the study's numbers have become outdated over the years, as changes have occurred in the Canadian population, in key health behaviors, in health service-use patterns, and in law enforcement practices. To fill this gap, the present study was initiated in 2003 and finalized in 2006. In addition to providing economic data relevant to health care planning, the study was conceptualized to provide the basis for calculation of avoidable costs resulting from a number of different policy changes (for methodology of estimating avoidable costs see Collins et al., 2006).

\footnotetext{
${ }^{\dagger}$ Correspondence may be sent to Jürgen Rehm at the above address or via email at: jtrehm@aol.com. He is also with the Addiction Research Institute, Zurich, Switzerland; the Department of Public Health Sciences, University of Toronto, Toronto, Ontario, Canada; and the Epidemiological Research Unit, Clinical Psychology and Psychotherapy, Technische Universität Dresden, Dresden, Germany. William Gnam is also with the Institute for Work and Health, Toronto, Ontario, Canada. Svetlana Popova is also with the Faculty of Social Work, University of Toronto, Toronto, Ontario, Canada. Dolly Baliunas and Benjamin Taylor are also with the Department of Public Health Sciences, University of Toronto, Toronto, Ontario, Canada. Serge Brochu is with the School of Criminology, University of Montreal, Montreal, Quebec, Canada. Benedikt Fischer is also with the Centre for Addictions Research of British Columbia, University of Victoria, Victoria, Canada. Jayadeep Patra is also with the Department of Human Development and Applied Psychology, University of Toronto, Toronto, Ontario, Canada.
} 


\section{Method}

A brief description of the methodology will follow; however, for a detailed account of the study methodology, see Rehm et al. (2006a).

\section{Main approach of the study}

This study was based on the revised International Guidelines for Estimating Costs of Substance Abuse (Single et al., 2003) as a cost-of-illness study, in which the impact of psychoactive substance use and misuse on the material welfare of Canadian society in 2002 was examined relative to a counterfactual scenario that assumed a situation of no substance use and misuse. Usually, the term abuse is used in economic literature, defined there as any substance use that involves a social cost (Collins and Lapsley, 1991). As the term abuse has a different definition in epidemiology and substance use research, we decided to use the term use and misuse, which covers costs attributable to all consequences associated with the use of psychoactive substances, rather than just those costs associated with physical dependence or heavy use, or with substance-use disorder as defined by the Diagnostic and Statistical Manual of Mental Disorders, Fourth Edition (American Psychiatric Association, 1995). This study used a modified prevalence-based human capital approach based on the concept of opportunity cost: The cost of resources spent on substance use and misuse is the benefit forgone from their best alternate use.

Only social costs were included in this study. This excluded so-called private costs, that is, costs accrued by people engaged in the activity of consuming psychoactive substances (e.g., costs to buy cigarettes or beer). Intangible costs (e.g., nonmonetary harms, such as pain and suffering) were also excluded from the study. Costs avoided as a result of beneficial health effects of substance use (e.g., cardioprotective effect of regular moderate drinking without heavy drinking occasions) were included, resulting in the reporting of only net costs of substance use.

\section{Estimating direct health care costs attributable to substance use and misuse}

The first step in estimating the health care costs was to quantify the proportion of substance-attributable morbidity and mortality. A list of more than 80 substance-attributable disease conditions associated with substance use and misuse was developed from reviews of epidemiological literature (Rehm et al., 2006a) of alcohol (Rehm et al., 2006b), illegal drugs (Popova et al., 2006b), and tobacco (Baliunas et al., 2007). The epidemiological criteria for determining which diseases were causally linked to substance use and misuse were based on the usual epidemiological criteria, with most weight accorded to consistency, biological mecha- nism, strength of association, and temporality (English et al., 1995; Hill, 1965; Rothman and Greenland, 1998). In addition, diseases that are, by definition, fully attributable to substance use and misuse (e.g., alcoholic cirrhosis of liver) were identified in the International Classification of Diseases Version 10 (ICD-10; World Health Organization, 2004).

Direct health care costs were estimated based on attributable fractions (AFs) (i.e., the proportion of a disease that can be attributed to the use of a certain substance). The AFs were calculated based on the prevalence of exposure and the relative risk of different exposure categories compared with no exposure using the following formula (see Walter, 1976, 1980):

$$
\mathrm{AF}=\left[\sum_{i=1}^{k} P_{i}\left(R R_{i}-1\right)\right] /\left[\sum_{i=0}^{k} P_{i}\left(R R_{i}-1\right)+1\right]
$$

where

- $i$ is the exposure category with baseline exposure or no exposure $i=0$;

- $\mathrm{RR}(i)$ is the relative risk at exposure level $i$ compared with no consumption; and

- $\mathrm{P}(i)$ is the prevalence of the $i$ th category of exposure.

The relative risks for each cause of disease and death were taken from the most recent comprehensive meta-analyses, separately by gender and age where applicable (see Rehm et al., 2006a, for further details).

The prevalence data for alcohol were based on the Canadian Addiction Survey (Canadian Centre on Substance Abuse, 2004) and adjusted for per capita consumption (Rehm et al., 2006b, 2007). Data on smoking prevalence were taken from the Canadian Community Health Survey cycle 2.1 (Statistics Canada, 2003) and data on prevalence of use of illegal drugs were collected from a variety of Canadian federal and provincial institutions (Popova et al., 2006a). For some disease categories, the AFs were derived directly from available statistics, including traffic statistics that categorize accidents that occur under the influence of alcohol. AFs were derived specifically by gender, age, and disease category. Based on the methodology, the AFs can be negative if substance use prevents any deaths or morbidity.

AFs were then applied to the respective outcome (e.g., mortality, hospital days). Direct health care costs attributable to substance use and misuse in all categories (hospitalizations, outpatient care, physician visits, and prescription drugs) were calculated as the product of the aggregate units of use, the average unit cost, and the disease-specific AF.

\section{Sources of data for health services and their costs}

Information on health service use was obtained from the Canadian Institute for Health Information (CIHI). Number 
of specialized inpatient and outpatient admissions as well as days of treatment of alcohol and illegal drug dependency were obtained from provincial ministerial officials or drug addiction program coordinators. The final report of the cost study details the sources of information by service category (Rehm et al., 2006a). CIHI data also provided the average unit costs for these categories, in most cases both on a national and provincial level.

\section{Estimating direct costs of law enforcement attributable to substance use and misuse}

Law enforcement costs related to substance use and misuse include costs of policing, costs of the court system, and costs of incarceration. Similar to the health sector, two categories of crimes could be distinguished. First, there were offenses, which by definition are $100 \%$ attributable to substance use and misuse, such as drug offenses or drunk driving. Second, there are offenses where only a portion is attributable to substance use and misuse; therefore, AFs have to be determined. Consider property crime as an example of this type of offense: Only a proportion of property crime is related to substance use and misuse (e.g., when a person engages in such crimes to finance his or her substance use). The proportion of nondrug crimes attributable to alcohol and illegal drugs was based on the estimates from the workgroup of Brochu and colleagues (2005). This study was conducted as part of the second Canadian cost study and provided gender-specific AFs for all crimes not fully attributable to substance use and misuse. The data were derived from interviews with a sample of federal and provincial jail inmates (Brochu et al., 2005; see also Pernanen et al., 2002). Inmates were given a standard interview on drug and/or alcohol use and criminal behavior, for the purposes of determining both immediate links and past history. From these data, the causal contribution of different substances in committing criminal offenses was determined. Although the samples tried to cover some of the variability with respect to severity and type of crime, they cannot be considered fully representative for Canada.

\section{Estimating indirect costs attributable to substance use and misuse: Baseline method}

The costs of productivity losses owing to substance-attributable premature death or disability were estimated using a modified human capital method that assumes that a pool of unemployed workers is available to replace the prematurely deceased workers across a mean replacement period of 3 months (Koopmanschap and Rutten, 1996). Productivity losses were calculated as the sum of lost wages during the replacement period and the monetized value of replacement workers' sacrifice of leisure for paid work, assuming that the societal opportunity cost of their leisure (i.e., the cost of forgone leisure) equals their marginal reservation wage (i.e., the lowest wage at which they are willing to work). To facilitate comparisons with past studies, we also calculated productivity costs using the traditional human capital method and the friction cost method (Koopmanschap and Rutten, 1996).

This study used a $5 \%$ discount rate as this is the most commonly used discount rate in costing studies and as such maximizes comparability with other valuation studies. By choosing 5\% as the discount rate for the baseline analysis, we followed the guidelines established by the Canadian Coordinating Office for Health Technology Assessment (1997).

\section{Productivity costs owing to premature mortality}

Using the aggregate numbers of lost years of life by gender and age group, the productivity cost of substancerelated premature mortality was calculated as the sum of the cost to replace the deceased worker (estimated based on gender-specific average wage, adjusted for gender- and age-specific labor force participation) and the discounted present value of the replacement worker's projected future stream of marginal reservation wages, adjusted for productivity growth as well as gender- and age-related labor force participation.

\section{Productivity costs owing to morbidity}

To estimate the productivity losses attributable to substance-related morbidity, multivariate linear regression models of income were estimated using data recorded in the Canadian Community Health Survey, Cycle 1.2 (CCHS c1.2; Statistics Canada, 2002) for respondents ages 15-74 years. Productivity losses owing to morbidity were then calculated as the difference between the predicted mean income of the survey respondents with and without substance use disorders. Because the CCHS c1.2 did not measure tobacco-related disorders, the productivity losses owing to tobacco use were calculated by multiplying the estimated productivity losses owing to alcohol use and misuse (determined from the CCHS c1.2) by the ratio of hospitalization days attributable to tobacco use to hospitalization days attributable to alcohol use and misuse. We estimated the number and mean age of Canadians permanently disabled from working owing to alcohol or illegal drug use and misuse from CCHS c1.2 data and estimated their productivity losses using methods similar to those for premature mortality.

\section{Results}

\section{Epidemiological results}

Morbidity. The morbidity results are summarized in Table 1. Overall, almost $18 \%$ of total acute care hospital days 
REHM ET AL.

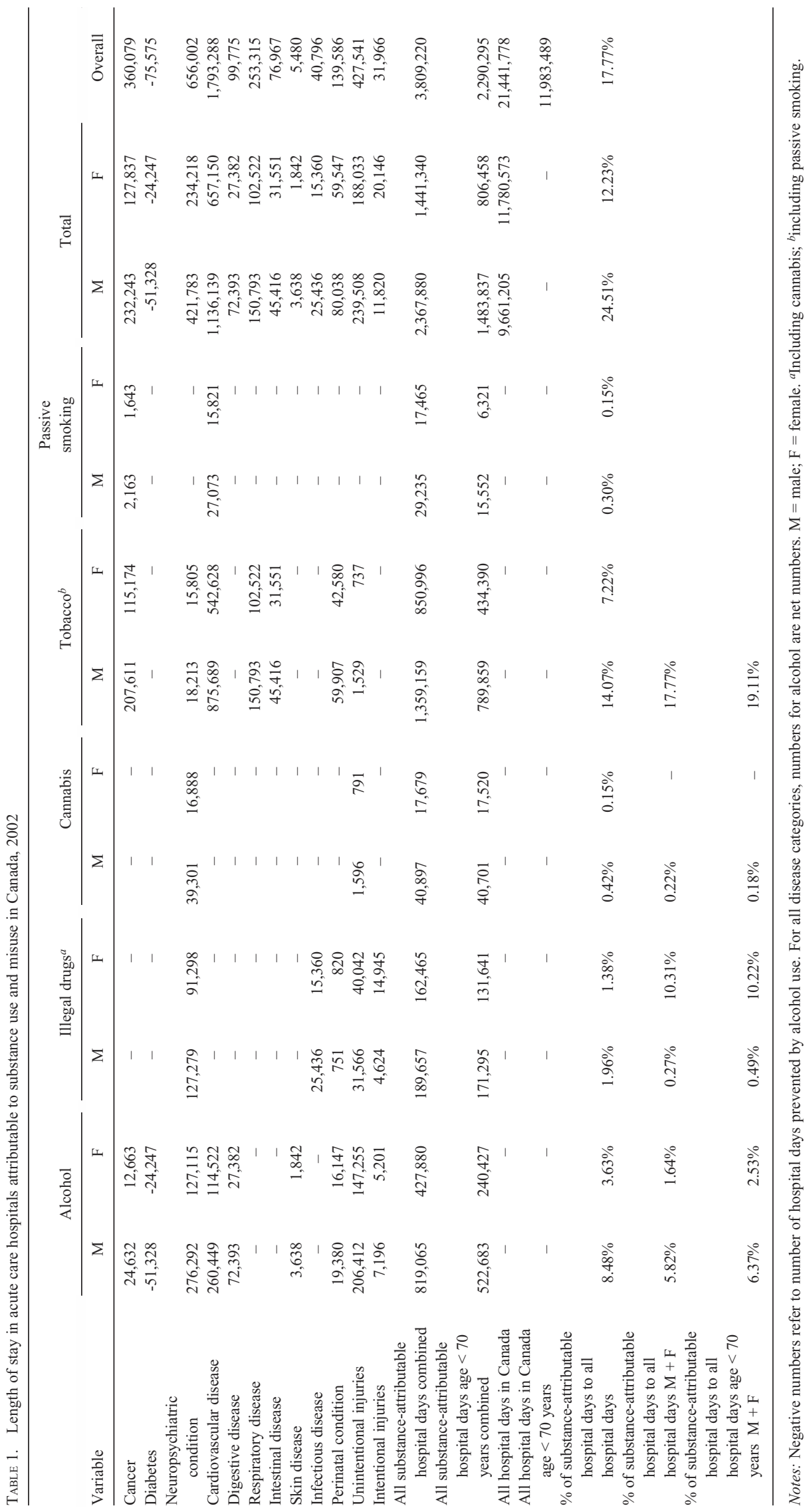


were the result of substance use and misuse in Canada 2002. Alcohol caused about 6\%, illegal drugs caused almost 2\%, and tobacco caused more than $10 \%$ of all hospital days. Among Canadians younger than age 70, 19\% of all hospital days were a result of substance use and misuse.

Table 2 presents the number of days spent in psychiatric hospital and inpatient and outpatient specialized centers owing to substance use and misuse. Overall, about $2 \%$ of all psychiatric hospital days were the result of alcohol use, and about 1\% the result of illegal drug use in Canada 2002. Specialized treatment accounted for approximately 3 million days each for alcohol and illegal drugs.

Mortality. Table 3 gives an overview of substance-attributable mortality for Canada for the year 2002. Tobacco caused more deaths than alcohol and illegal drugs combined, although many of the tobacco-related deaths occurred later in life. Alcohol-attributable deaths are a net estimate that incorporates the cardioprotective effect of regular light to moderate drinking (Rehm et al., 2003).

More than $19 \%$ of all deaths and about $30 \%$ of the deaths among individuals younger than age 70 in Canada were caused by substance use and misuse. This total represents a slight overestimate owing to double-counting where there is overlap between substance-attributable deaths. For example, esophageal cancer is influenced by the interaction of alcohol and tobacco use (Taylor and Rehm, 2005). However, the overall effect of this interaction between different substances is not very large: Collins and Lapsley (2002) found that the double-counting described above led to an overestimate of $2.2 \%$ of the total mortality caused by addictive substances in Australia in 1998 and 1999.

Potential years of life lost. In 2002, Canadians lost about 516,000 potential years of life owing to tobacco, 148,000 years owing to alcohol, and 62,000 years owing to illegal drugs, respectively representing about $17 \%, 5 \%$, and $2 \%$ of all potential life years lost by Canadians. Potential years of life lost estimates are presented in Table 4.

\section{Cost results}

Table 5 gives an overview of the social costs attributable to substance use and misuse by cost category for 2002 .

The estimated cost of substance use and misuse in Canada was Can. \$39.8 billion in 2002. The economic costs of tobacco use and misuse were estimated at Can. \$17 billion. This represented almost $43 \%$ of total substance use and misuse costs. Alcohol accounted for about Can. \$14.6 billion in costs, which represented almost $37 \%$ of the total costs of substance use and misuse. Costs of illegal drugs were estimated to be approximately Can. $\$ 8.2$ billion, which represented almost $21 \%$ of the total costs of substance use and misuse.

The total cost per capita for substance use and misuse was about Can. $\$ 1,267$ in 2002: Can. $\$ 463$ for alcohol, Can. \$262 for illegal drugs, and Can. \$541 for tobacco.

The two major direct cost categories attributable to substance use and misuse were health care costs, accounting for more than $22 \%$ (Can. $\$ 8.8$ billion), and costs for law enforcement, accounting for about $14 \%$ (Can. $\$ 5.4$ billion) of the overall costs. Health care costs were by far the largest category of direct costs, comprised mainly of costs arising from acute care hospitals but also from psychiatric and other specialized treatment institutions. Although the aggregate number of hospitalization days has declined markedly in the last decade, aggregate hospital days attributable to substance use and misuse did not follow this trend and stayed at about the same level as in 1992 (Rehm et al., 2006a). The costs of law enforcement attributable to substance use and misuse were considerable for both illegal drugs and alcohol; overall, they constituted more than one third of the total direct costs. Overall, the level of costs for law enforcement attributable to substance use and misuse can serve as an important marker that substance use and misuse is not only a health problem but a larger public health and social concern as well. Compared with the health

TABLE 2. Days spent in psychiatric hospitals and specialized treatment attributable to substance use and misuse in Canada, 2002

\begin{tabular}{lrrc}
\hline Variable & Alcohol & Illegal drugs $^{a}$ & Cannabis $^{-}$ \\
\hline Psychiatric treatment days & & & \\
$\quad$ Males & 38,602 & 21,881 & 2,895 \\
$\quad$ Females & 15,512 & 9,627 & 1,105 \\
$\quad$ Total & 54,114 & 31,508 & 4,000 \\
$\quad \begin{array}{l}\text { All treatment days in Canada } \\
\text { \% of substance-attributable treatment }\end{array}$ & $1,432,547$ & $2,110,102$ & - \\
$\quad$ days to all treatment days & $1.53 \%$ & $0.89 \%$ & $0.11 \%$ \\
Specialized treatment days & & & - \\
$\quad$ Males & $2,102,148$ & $1,832,510$ & - \\
$\quad$ Females & 916,540 & $1,019,319$ & - \\
$\quad$ Total & $3,018,688$ & $2,851,829$ & - \\
\hline
\end{tabular}

${ }^{a}$ Including cannabis. 
REHM ET AL.

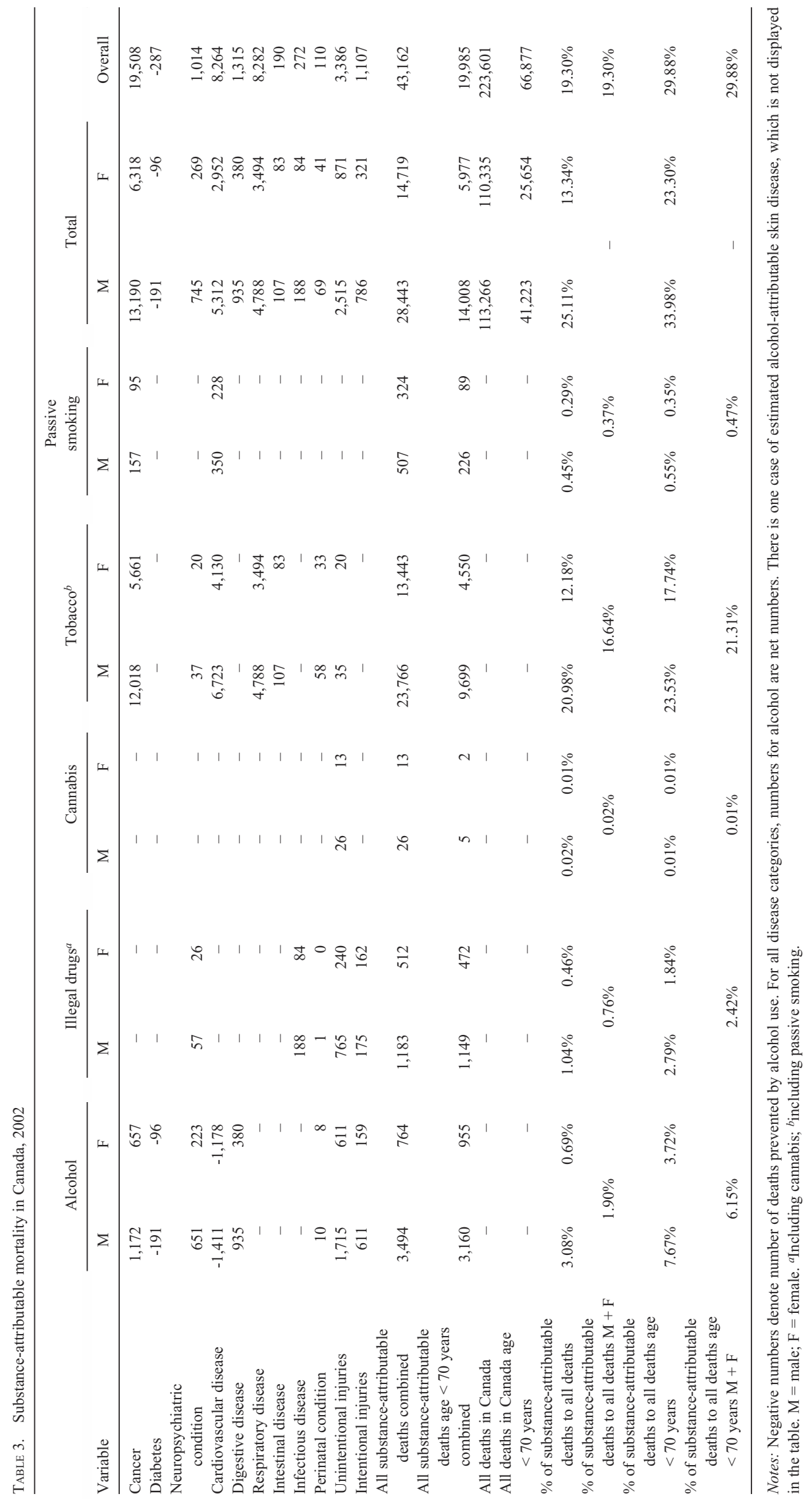


TABLE 4. Potential years of life lost (PYLL) attributable to substance use and misuse in Canada, 2002, all ages

\begin{tabular}{lrrrr}
\hline Variable & $\mathrm{M}$ & $\mathrm{F}$ & Total & \% of all PYLL \\
\hline Alcohol & 113,380 & 34,191 & 147,571 & $4.77 \%$ \\
Illegal drugs $^{a}$ & 42,306 & 19,805 & 62,110 & $2.01 \%$ \\
Cannabis $^{\text {Tobacco }}{ }^{b}$ & 989 & 488 & 1,478 & $0.05 \%$ \\
Passive smoking & 316,417 & 199,191 & 515,607 & $16.68 \%$ \\
Substance-attributable & 6,967 & 4,277 & 11,244 & $0.36 \%$ \\
$\quad$ PYLL & 472,103 & 253,187 & 725,288 & \\
All PYLL in Canada & $1,618,019$ & $1,473,557$ & $3,091,576$ & \\
\% of substance-attributable & & & & \\
$\quad$ PYLL & $29.18 \%$ & $17.18 \%$ & $23.46 \%$ & \\
\hline
\end{tabular}

Notes: Numbers for alcohol are net numbers (i.e., taking into consideration the beneficial effects of alcohol use). $\mathrm{M}=$ male; $\mathrm{F}=$ female. ${ }^{a}$ Including cannabis; ${ }^{b}$ including passive smoking.

TABLE 5. The social costs of alcohol, illegal drugs and tobacco use and misuse in Canada, 2002, in millions of Canadian dollars

\begin{tabular}{|c|c|c|c|c|}
\hline Variable & Alcohol & Illegal drugs & Tobacco & Total ADT \\
\hline $\begin{array}{l}\text { 1. Direct health care costs: total } \\
\text { 1.1 Morbidity }\end{array}$ & $3,306.2$ & $1,134.6$ & $4,360.2$ & $8,800.9$ \\
\hline - Acute care hospitalization & $1,458.6$ & 426.4 & $2,551.2$ & $4,436.2$ \\
\hline - Psychiatric hospitalization & 19.6 & 11.5 & - & 31.2 \\
\hline 1.2 Inpatient specialized treatment & 754.9 & 352.1 & - & $1,107.1$ \\
\hline 1.3 Outpatient specialized treatment & 52.4 & 56.3 & - & 108.7 \\
\hline 1.4 Ambulatory care: physician fees & 80.2 & 22.6 & 142.2 & 245.0 \\
\hline 1.5 Family physician visit & 172.8 & 48.8 & 306.3 & 527.9 \\
\hline 1.6 Prescription drugs & 767.6 & 216.8 & $1,360.5$ & $2,344.9$ \\
\hline 2. Direct law enforcement costs & $3,072.2$ & $2,335.5$ & - & $5,407.8$ \\
\hline 2.1 Police & $1,898.8$ & $1,432.0$ & - & $3,330.7$ \\
\hline 2.2 Courts & 513.1 & 330.6 & - & 843.7 \\
\hline 2.3 Corrections (including probation) & 660.4 & 573.0 & - & $1,233.4$ \\
\hline Direct costs for prevention and research & 53.0 & 16.5 & 78.1 & 147.6 \\
\hline 3.1 Research & 17.3 & 8.6 & 9.0 & 34.9 \\
\hline 3.2 Prevention programs & 33.9 & 7.9 & 69.1 & 110.9 \\
\hline 3.3 Salaries and operating funds & 1.8 & - & - & 1.8 \\
\hline Other direct costs & 996.1 & 79.1 & 87.0 & $1,162.2$ \\
\hline 4.1 Fire damage & 156.5 & - & 86.5 & 243.0 \\
\hline 4.2 Traffic accident damage & 756.9 & 67.0 & - & 823.9 \\
\hline $\begin{array}{l}\text { 4.3 Losses associated with the workplace } \\
\text { 4.3.1 EAP and health promotion }\end{array}$ & 17.0 & 6.6 & 0.5 & 24.1 \\
\hline programs & 17.0 & 4.2 & 0.5 & 21.7 \\
\hline 4.3.2 Drug testing in the workplace & - & 2.4 & $\mathrm{NA}$ & 2.4 \\
\hline $\begin{array}{l}\text { 4.4 Administrative costs for transfer } \\
\text { payments } \\
\text { 4.4.1 Social welfare and other }\end{array}$ & 65.8 & 5.4 & 0.0 & 71.3 \\
\hline programs & 4.3 & - & - & 4.3 \\
\hline 4.4.2 Workers' compensation & 61.5 & 5.4 & - & 66.9 \\
\hline $\begin{array}{l}\text { 5. Indirect costs: productivity losses } \\
\text { (main scenario) }\end{array}$ & $7,126.4$ & $4,678.6$ & $12,470.9$ & $24,275.9$ \\
\hline 5.1 Owing to long-term disability & $6,163.9$ & $4,408.4$ & $10,536.8$ & $21,109.1$ \\
\hline $\begin{array}{l}5.2 \text { Owing to short-term disability } \\
\text { (days in bed) }\end{array}$ & 15.9 & 21.8 & 24.4 & 62.0 \\
\hline $\begin{array}{l}\text { 5.3 Owing to short-term disability } \\
\text { (days with reduced activity) }\end{array}$ & 23.6 & -0.1 & 36.2 & 59.8 \\
\hline 5.4 Owing to premature mortality & 923.0 & 248.5 & $1,873.5$ & $3,045.0$ \\
\hline Total & $14,554.0$ & $8,244.3$ & $16,996.2$ & $39,794.4$ \\
\hline Total per capita, in Can. \$ & 463 & 262 & 541 & 1,267 \\
\hline Total as $\%$ of all substance-related costs & $36.6 \%$ & $20.7 \%$ & $42.7 \%$ & $100.0 \%$ \\
\hline
\end{tabular}

Notes: Categories in italics are sub-categories of immediate prior category. ADT $=$ alcohol, illegal drugs, and tobacco; $\mathrm{NA}=$ not applicable; "-" = not available; EAP = employee assistance programs. 
TABLE 6. Sensitivity analyses of substance-attributable indirect costs (in millions of Canadian dollars)

\begin{tabular}{lrrr}
\hline Variable & $\begin{array}{c}\text { Main } \\
\text { scenario }\end{array}$ & $\begin{array}{c}\text { Friction } \\
\text {-cost } \\
\text { approach }\end{array}$ & $\begin{array}{c}\text { Human- } \\
\text { capital } \\
\text { approach }\end{array}$ \\
\hline Costs of productivity losses & & & \\
owing to long-term disability & & & \\
$\quad$ Alcohol & $6,163.9$ & 133.1 & $9,848.5$ \\
$\quad$ Illegal drugs & $4,408.4$ & 93.1 & $7,046.9$ \\
$\quad$ Tobacco & $10,536.8$ & 235.9 & $16,821.6$ \\
$\quad$ Total & $21,109.1$ & 462.1 & $33,717.0$ \\
Costs of productivity losses & & & \\
owing to premature mortality & & & \\
$\quad$ Alcohol & 923.0 & 30.0 & $1,822.7$ \\
$\quad$ Illegal drugs & 248.5 & 7.2 & 468.6 \\
$\quad$ Tobacco & $1,873.5$ & 68.7 & $3,148.6$ \\
$\quad$ Total & $3,045.0$ & 105.8 & $5,440.0$ \\
$\quad$ Total & & & \\
\hline
\end{tabular}

and the law enforcement sector, all the other direct costs (e.g., prevention and research, fire damage, traffic accident damage, losses associated with the workplace, and administrative costs for transfer payments) are of lesser economic weight.

Based on the methods used in the baseline approach, the productivity losses owing to substance use and misuse were Can. $\$ 24.3$ billion, constituting the largest part of the social costs $(61 \%)$. This finding is consistent with all previous social cost studies of substance use and misuse (e.g., Collins and Lapsley, 2002; Single et al., 1996). Among productivity losses the costs owing to long-term disability were the largest component, at Can. $\$ 21.1$ billion (87\% of the total).

The methods used to calculate indirect costs are variable and are the subject of ongoing debate. To facilitate comparisons with other studies, Table 6 presents sensitivity analyses of indirect costs comparing the baseline approach with the friction cost and traditional human capital methods. Depending on the method, the indirect cost estimates range from Can. $\$ 567.9$ million to Can. $\$ 39.2$ billion. For both the baseline approach and the traditional human capital method, indirect costs remain the largest social cost.

\section{Discussion}

There are several limitations of this study. For various methodological reasons or simply because the data were not available, some costs associated with substance use and misuse were not included. Thus, prescription drug use and misuse was not included simply because the minimum data were not available in Canada to make a comprehensive cost analysis.

Although this study represents an improvement in estimating substance use and misuse costs linked to crime, it could have benefited from more detailed policing data to estimate enforcement costs. In the case of tobacco-related crime, for example, no enforcement estimate was even possible, as there were no data that allow for the quantification of this cost category, even though there clearly had been law enforcement activities attributable to tobacco smuggling. Finally, this study did not assess the lost productivity of people in prison convicted of a substance-related crime.

The issue of causality with regard to alcohol-related crime, and especially illegal drug-related crime, should be also acknowledged as a limitation of this study. For example, even in cases where a person consumed alcohol or illegal drugs before committing a crime and even when the respondent admitted that the crime would not have taken place without them, there is no certainty that the crime can be causally attributed to alcohol or drug consumption. Thus, the attribution of alcohol or drugs as a causal factor in the crime may contain bias, reflecting the limitations of the methodologies used, which are based on self-report.

There are several approaches used in the economic cost studies, including the human-capital approach, the frictioncost approach, and the hybrid approach. In this study, the latter approach was used as the best suitable method for current labor market conditions in Canada. The hybrid approach assumes availability of replacement workers (labor markets in Canada are not at full employment); thus, the value of societal production losses resulting from premature deaths is equal to the production lost during the replacement (friction) period plus the value of leisure sacrificed by replacement workers. The human-capital approach overestimates the value of societal losses by assuming the loss is permanent - that the prematurely deceased workers cannot be replaced. The underlying assumption of full employment is not realistic in contemporary Canadian labor markets, where involuntary unemployment has been a persistent feature over several years. The friction-cost approach underestimates the production losses, as it assumes that the societal opportunity cost of labor is zero- that is, that the sacrifice of replacement workers' leisure for work has no monetary value. The hybrid approach recognizes both the value of leisure sacrificed for work as well as existing involuntary unemployment.

At almost Can. $\$ 40$ billion in 2002, the social costs of substance use and misuse in Canada were considerable, and they appear to have increased over the past decade, particularly for illegal drugs. Neither these recent costs nor the trend of increasing social costs is necessary, as the intervention literature demonstrates that there are numerous feasible, cost-effective, and evidence-based approaches to reducing substance-attributable costs. For example, alcohol control measures such as pricing, taxation, state monopolies to prevent selling to minors, and strict and consistent enforcement of traffic and workplace safety laws have been shown to be effective and cost-effective (Babor et al., 2003; Chisholm et al., 2004) methods to contain or reduce the social costs of alcohol. For tobacco, interventions such as 
taxation, clean indoor air laws, a comprehensive ban on advertising, and dissemination of information on the health risks of tobacco have also been shown to be cost effective in all World Health Organization subregions (Shibuya et al., 2003). Indeed, some of the reduced burden of disease in Canada can probably be attributed to the improved tobacco control measures over the past decade. For illegal drugs, the evidence is much less clear, but some countries such as Switzerland (Büechi and Minder, 2001), France, and Spain (Ramirez-Jonville, 2006) seem to have developed effective strategies to reduce harm and costs from illegal drugs.

Estimating social costs is important not only for understanding current realities but also for future programming and policy. However, estimating social costs is only the first step in future planning. For concrete programming and policy making, it is necessary to know which social costs are avoidable costs. The costs presented in this article aggregate all costs attributable to substance use and misuse, no matter whether or to what degree they are avoidable. To give one example, if all tobacco consumption stopped today, there would still be tobacco-attributable lung cancers for many years to come. There are many other examples, and, in the past year, there have been efforts to systematically determine the avoidable costs attributable to substance use and misuse (Collins et al., 2006; Rehm et al., 2006c). Given the level of substance use- and misuse-related costs in Canada, it is important to start the work on quantifying avoidable costs to have more focused and relevant information from which to plan programs and policies to reduce these costs.

\section{Acknowledgments}

The authors thank David Collins, Helen Lapsley, and Eric Single for their helpful comments on an earlier version of this manuscript.

\section{References}

American Psychiatric Association. Diagnostic and Statistical Manual of Mental Disorders (DSM-IV), Primary Care, Washington, DC, 1995.

Anderson, P. and Baumberg, B. Alcohol in Europe. A Report of the European Commission, London, England: Institute of Alcohol Studies, 2006.

Andlin-Sobocki, P. and Rehm, J. Cost of addiction in Europe. Europ. J. Neurol. 12 (Suppl. No. 1): 28-33, 2005.

Babor, T., Caetano, R., Casswell, S., Edwards, G., Giesbrecht, N., Graham, K., Grube, J., Gruenewald, P., Hill, L., Holder, H., Homel, R., Österberg, E., Rehm, J., Room, R., and Rossow, I. (Eds.) Alcohol: No Ordinary Commodity. Research and Public Policy, New York: Oxford Univ. Press, 2003.

Baliunas, D., Patra, J., Rehm, J., Popova, S., Taylor, B., and Kaiserman, M. Smoking-attributable mortality in Canada 2002: Conclusions for prevention and policy. Chronic Dis. Can. 27: 152-164, 2007.

Brochu, S., Cousineau, M., and Sun, F. Crime Associated with Alcohol and Drugs Among Offenders in Ontario Provincial Prisons, Ottawa, Canada: Canadian Centre on Substance Abuse, 2005.
BÜECHI, M. ANd Minder, U. Swiss Drug Policy: Harm Reduction and HeroinSupported Therapy, Vancouver, Canada: The Frasier Institute, 2001.

Canadian Centre on Substance Abuse. Canadian Addiction Survey 2004: Microdata eGuide, Ottawa, Canada: Canadian Centre on Substance Abuse, 2004.

Canadian Coordinating Office for Health Technology Assessment. Guidelines for the Economic Evaluation of Pharmaceuticals: Canada, 2nd Edition, Ottawa, Canada: Canadian Coordinating Office for Health Technology Assessment, 1997.

Chisholm, D., Rehm, J., van Ommeren, M., and Monteiro, M. Reducing the global burden of hazardous alcohol use: A comparative cost-effectiveness analysis. J. Stud. Alcohol 65: 782-793, 2004.

Collins, D.J. and Lapsley, H.M. Estimating the Economic Costs of Drug Abuse in Australia. National Campaign Against Drug Abuse, Monograph Series No. 15, Canberra, Australia: Australian Government Publishing Service, 1991

Collins, D.J. and Lapsley, H.M. Counting the Cost: Estimates of the Social Costs of Drug Abuse in Australia in 1998-9. National Drug Strategy Monograph Series No. 49, Canberra, Australia: Commonwealth Department of Health and Ageing, 2002.

Collins, D., Lapsley, H., Brochu, S., Easton, B., Pérez-Gómez, A., Rehm, J., AND Single, E. International Guidelines for the Estimation of the Avoidable Costs of Substance Abuse, Ottawa, Canada: Health Canada, 2006.

English, D.R., Holman, C.D.J., Milne, E., Winter, M.G., Hulse, G.K., Codde, J.P., Bower, C.I., Corti, B., de Klerk, N., Knuiman, M.W., KuRinczuk, J.J., Lewin, G.F., and Ryan, G.A. The Quantification of Drug Caused Morbidity and Mortality in Australia 1995, Canberra, Australia: Commonwealth Department of Human Services and Health, 1995.

Ezzati, M., Lopez, A.D., Rodgers, A., Vander Hoorn, S., Murray, C.J.L., and The Comparative Risk Assessment Collaborating Group. Selected major risk factors and global and regional burden of disease. Lancet 360: 1347-1360, 2002.

HaRwood, H.J. Updating Estimates of the Economic Costs of Alcohol Abuse in the United States: Estimates, Update Methods, and Data, Bethesda, MD: National Institute on Alcohol Abuse and Alcoholism, 2000.

Hitl, A.B. The environment and disease: Association or causation? Proc. Royal Soc. Med. 58: 295-300, 1965.

Koopmanschap, M.A. AND Rutten, F.F. A practical guide for calculating indirect costs of disease. Pharmacoeconomics 10: 460-466, 1996.

Pernanen, K., Cousineau, M.-M., Brochu, S., and Sun, F. Proportions of Crimes Associated with Alcohol and Other Drugs in Canada, Ottawa: Canadian Centre on Substance Abuse, 2002.

Popova, S., Rehm, J., and Fischer, B. An overview of illegal opioid use and health services utilization in Canada. Publ. Hlth 120: 320-328, 2006a.

Popova, S., Rehm, J., and Patra, J. Illegal drug-attributable mortality and potential years of life lost in Canada 2002: Implications for prevention and policy. Contemp. Drug Probl. 33: 343-366, $2006 \mathrm{~b}$.

Ramirez-Jonville, A. Toxicomanies: La politique de reduction des risques en France et en Espagne (Drug addiction: Harm reduction policies in France and Spain). Presse Med. 35: 1151-1161, 2006.

Rehm, J., Baliunas, D., Brochu, S., Fischer, B., Gnam, W., Patra, J., Popova, S., Sarnocinska-Hart, A., and Taylor, B. The Costs of Substance Abuse in Canada 2002, Ottawa, Canada: Canadian Centre on Substance Abuse, 2006a.

Rehm, J., Klotsche, J., AND Patra, J. Comparative quantification of alcohol exposure as risk factor for global burden of disease. Int. J. Meth. Psychiat. Res. 16: 66-76, 2007.

Rehm, J., Patra, J., and Popova, S. Alcohol-attributable mortality and potential years of life lost in Canada 2001: Implications for prevention and policy. Addiction 101: 373-384, $2006 \mathrm{~b}$. 
Rehm, J., Sempos, C.T., And Trevisan, M. Average volume of alcohol consumption, patterns of drinking and risk of coronary heart disease: A review. J. Cardiovasc. Risk 10: 15-20, 2003.

Rehm, J., Taylor, B., Patra, J., And Gmel, G. Avoidable burden of disease: Conceptual and methodological issues in substance abuse epidemiology. Int. J. Meth. Psychiat. Res. 15: 191-211, $2006 \mathrm{c}$.

Rothman, K.J. and Greenland, S. Causation and casual inference. In: Rothman, K.J. and Greenland, S. (Eds). Modern Epidemiolgy, 2nd Edition, Philadelphia, PA: Lippincott Williams \& Wilkens, Philadelphia, PA: 1998, pp. 7-28.

Shibuya, K., Ciecierski, C., Guindon, E., Bettcher, D.W., Evans, D.B., and Murray, C.J.L. WHO Framework Convention on Tobacco Control: Development of an evidence based global public health treaty. Brit. Med. J. 327: 154-157, 2003.

Single, E., Collins, D., Easton, B., Harwood, H., Lapsley, H., Kopp, P., AND Wilson, E. International Guidelines for Estimating the Costs of Substance Abuse, 2nd Edition, Geneva, Switzerland, World Health Organization, 2003.

Single, E., Robson, L., Rehm, J., And Xie, X. Morbidity and mortality attributable to alcohol, tobacco, and illicit drug use in Canada. Amer. J. Publ. Hlth 89: 385-390, 1999.

Single, E., Robson, L., Xie, X., and Rehm, J. The Costs of Substance Abuse in Canada: Highlights of a Major Study of the Health, Social and Economic Costs Associated with the Use of Alcohol, Tobacco and Illicit Drugs, Ottawa, Canada: Canadian Centre on Substance Abuse, 1996.

Single, E., Robson, L., Xie, X., and Rehm, J. The economic costs of alcohol, tobacco and illicit drugs in Canada, 1992. Addiction 93: 9911006, 1998.

Statistics Canada. The 2002 Canadian Community Health Survey, Cycle 1.2, Mental Health and Well-Being, Original Micro Data Documentation (Master Data File), 2002.

Statistics Canada. Canadian Community Health Survey, Cycle 2.1, Public Use Microdata File (82M0013XCB), Ottawa, Canada: Statistics Canada, 2003.

TAYlor, B. AND ReHM, J. Moderate alcohol consumption and diseases of the gastrointestinal system: A review of pathophysiological processes. Digest. Dis. 23 (3-4): 177-180, 2005.

WALTER, S.D. The estimation and interpretation of attributable risk in health research. Biometrics 32: 829-849, 1976.

Walter, S.D. Prevention of multifactorial disease. Amer. J. Epidemiol. 112: 409-416, 1980.

World Health Organization. International Statistical Classification of Diseases and Related Health Problems, Tenth Revision (ICD-10), 2nd Edition, Vols. 1 and 2, Geneva, Switzerland: World Health Organization, 2004. 